lilar ist, und filtriert dann durch ein dichtes Filter. Der Niederschlag wird vollständig aufs Filter gebracht und das Becherglas mit wenig Waschflüssigkeit $(8 \mathrm{~g}$ Kaliumjodat und $50 \mathrm{ccm}$ konz. Salpetersäure auf ein Liter) gewaschen. Nach völligem Ablaufen der Flüssigkeit wird der Filtrierinhalt mit obiger Waschflüssigkeit ins Fällungsgefäss zurückgespült, mit einem Glasstab zerdrückt und kräftig geschüttelt. Nun wird der Niederschlag abermals auf dassselbe Filter gebracht, nach kurzem Stehenlassen mit heissem Wasser ins Becherglas gespritzt und unter beständigem Rühren durch Eintropfenlassen von konz. Salpetersäure bei Vermeidung eines Überschusses in Lösung gebracht. Gewöhnlich erfordert $0,1 g$ Cerioxyd 20-25 $\mathrm{cm}$ der Säure. Zu dieser Lösung kommt etwa $\cap, 25 \mathrm{~g}$ Kaliumbromat und die zur ursprünglichen Abscheidung angewandte Menge Kaliumjodat. Sollte durch die Zugabe der Jodatlösung eine unzulässige Verdünnung der Fällungsflüssigkeit eintreten, so empfiehlt es sich, festes Kaliumjodat in möglichst wenig heisser Salpetersäure $(1: 2)$ zu lösen und damit zu versetzen. Die vollkommen kalte, abgesetzte Fällung wird durch ein dichtes Filter filtriert, mit wenig vorgeschriebener Waschflüssigkeit gewaschen, samt Filter ins Fällungsgefäss zurückgebracht und mit 5-8, kristallisierter Oxalsäure und $50 \mathrm{ccm}$ Wasser langsam erwärmt. Schliesslich ist es notwendig, zur Vertreibung des freigewordenen Jods zu kochen. Nach mehrstündigem Stehen wird das Ceroxalat mit den beigemengten Filterresten filtriert, mit kaltem Wasser gewaschen, im Platintiegel über der Gebläseflamme geglüht und als $\mathrm{Ce}_{2}$ gewogen.

Diese Methode eignet sich zur genauen Bestimmang des Cers in Gegenwart grösserer Mengen anderer seltenen Erden. Brzeziner.

\title{
Für die Bestimmung von Zirkon in Erzen und Legierungen
} gibt J. D. Ferguson ${ }^{1}$ ) folgende Methode an:

Bei Erzen oder bei Ferrozirkon werden $0,5 g$ der feinpulverigen Probe mit der zehnfachen Menge Soda im Platintiegel geschmolzen, die Schmelzlösung salzsauer gemacht und nach Zugabe weiterer $20 \mathrm{ccm}$ Salzsäure zur Trockne verdampft Bei Stählen geschieht der Aufschluss innerhalb weniger Minuten in der Weise, dass $3 g$ der Späne in einem Becherglas mit $15 \mathrm{ccm}$ heissem Wasser, $15 \mathrm{ccm}$ konz. Salzsäure und $1 \mathrm{ccm}$ konz. Salpetersäure behandelt werden, wobei letztere tropfenweise bis zur völligen Lösung zugesetzt werden soll. Nach Zufügen von $6 \mathrm{ccm}$ konz. Schwefelsäure wird zur Trockne verdampft, mit $30-50 \mathrm{ccm}$ heissem Wasser und $1 \mathrm{ccm}$ Schwefelsäure erhitzt und, sobald Lösung erfolgt ist, durch Absaugen von der Kieselsäure filtriert. Diese wird nacheinander mit heissem Wasser, heisser verd. Salzsäure und nochmals mit heissem Wasser gewaschen, verascht, mit Flussäure und mindestens $2 \mathrm{ccm}$ Schwefelsäure verflüchtigt und die Lösung des verbleibenden Rückstandes zur Hauptlösung gebracht.

1) Eng. Min. Journ. 106, 793 (1918); d. Chem. Zentrbl. 90, II, 544 (1919). 
Die folgenden Angaben gelten in gleicher Weise für die Untersuchung von Erzen, Legierungen oder Stahlen.

Die l,ösungen werden bis zur schwachsauren. Reaktion mit Ammoniak versetzt und mit $6 \mathrm{ccm}$ Ammoniumbisulfitlösung ') zur Reduktion des Eisens erhitzt. Hierauf wird Ammoniak bis zur beginnenden Ausscheidang eines Niederschlages zngefügt und schliesslich 10 Tropfen konz. Salzsäure - - bei der Fällung des Zirkons mit Phenylhydrazin (oder $2 \mathrm{~cm}$ konz. Schwefelsäure, falls die Fällung als Phosphat erfolgt) zugegeben. In der auf $400 \mathrm{ccm}$ verdünnten zum Kochen erhitzten Lösung werden mit $4 \mathrm{ccm}$ Phenylhydrazinlösung das Zirkon, das Aluminium und geringe Eisenmengen gefällt. Nach halbstündigem Stehen in der Wärme wird der Niederschlag filtriert, einigemale mit Wasser gewaschen, in verd. Salzsäure und Schwefelsäure gelöst und die mit $1 \mathrm{ccm}$ Bisulfitlösung reduzierte Flüssigkeit nochmals gefällt, wobei sich nun der Niederschlag eisenfrei abscheidet. In dem geglühten und gewogenen Niederschlag kann das Zirkon vom Aluminium durch Kupferron getrent werden, oder die Oxyde werden mit Soda geschmolzen und die Schmelze mit heissem Wasser und Natronlauge behandelt. Dadurch geht das Aluminium in Lösung, während Natriumzirkonat zurückbleibt. Dieser Räckstand wird filtriert, geglüht, mit Kaliumpyrosulfat geschmolzen und aus der Wasserlösung der Schmelze mit Ammoniak (bei Anwesenheit von Eisen besser mit Phenylhydrazin) gefällt. Ferner wird nach der Fällung des Zirkons als Phosphat nach vorhergehender Reduktion und Neutralisation, die Trennung des Zirkons vom Aluminium mittels Kupferrons and die Bestimmung und Trennung des Zirkons vom Eisen als Phosphat besprochen.

Brzeziner.

III. Chemische Analyse organischer Stoffe.

1. Elementaranalyse.

Silberasbest, Bleichromat- und Bleihyperoxydasbest empfiehlt o. Binder ${ }^{2}$ ) bei Verbrennungen. Zur Absorption von Chlor èignet sich sebr gut molekulares Silber, das eine weit grössere Oberfläche hat und ohne Zweifel viel energiseher wirkt als Blech oder Draht.

Man erhält dasselbe, indem man in eine ammoniakalische Lösung von salpetersaurem Silber eine Zinkstange stellt. Das ausgewaschene Silber wird getrocknet and mit ausgeglühtem Asbest in einer Pülverflasche geschüttelt.

Ebenso stellt man aus gepulvertem Bleichromat und Bleihyperoxyd mit Asbest die entsprechenden Gemische her.

Oswald.

Einen Beitrag zur Bestimmung des Quecksilbers im Quecksilbersalizylat liefert A. Costantin $0^{3}$ ), indem er über die elektrolytische

1) Dargestellt durch Einleiten von schwefliger Säure in konz Ammoniak. - 2) Chem. Ztg. 42, 522 (1918). - 3) Giorn. Farm. Chim. 67, 7; durch Chem. Zentrbl. 90, II, 4 (1919). 